Review

\title{
Responses of the ciliates Tetrahymena and Paramecium to external ATP and GTP
}

\author{
Todd M. Hennessey \\ Department of Biological Sciences, University at Buffalo, Amherst, New York, USA
}

Received 31 August 2004; accepted in revised form 13 October 2004

Key words: adaptation, ATP, binding, ecto-ATPase, electrophysiology, GTP, mutants, Paramecium, Tetrahymena

\begin{abstract}
The unicellular ciliates Paramecium and Tetrahymena are the simplest eukaryotic cells to show reliable depolarizing responses to micromolar concentrations of external ATP and GTP. Their simplicity allows for combined analysis of swimming behavior, electrophysiology, receptor binding, behavioral mutant and drug screens as well as molecular genetic approaches such as RNAi and gene knockouts experiments. ATP and GTP are depolarizing chemorepellents in both ciliates, producing measurable receptor potentials and $\mathrm{Ca}^{2+}$-based action potentials that are correlated with jerking behaviors called avoiding reactions (AR). GTP also causes repetitive continuous ciliary reversals (CCR) and oscillating plateau depolarizations in Paramecium. Both ciliates show high affinity, saturable external binding of ${ }^{32} \mathrm{P}-\mathrm{GTP}$ and ${ }^{32} \mathrm{P}$-ATP but GTP does not compete for ATP binding and vice versa. Chemosensory adaptation occurs after continued exposure (15 $\mathrm{min})$ to these ligands, producing a loss of external binding and forward swimming. However, cells adapted to ATP still bind and respond to GTP and GTP-adapted cells still bind and respond to ATP. This, combined with pharmacological analyses, suggests that there are two separate receptor systems: A metabotropic ATP receptor pathway and a different, novel GTP receptor pathway. A Paramecium mutant (ginA) lacks the GTP-induced oscillating depolarizations but does show AR in GTP, unveiling isolated GTP-receptor potentials for study. An ecto-ATPase is also present that may be involved in inactivation of ATP and GTP signals. Gene knockout experiments are currently underway to determine the roles of the ecto-ATPase and a putative 7-transmembrane spanning receptor in these responses.
\end{abstract}

\section{Introduction}

The ciliates Paramecium and Tetrahymena are excellent model systems for eukaryotic sensory transduction studies. The advantages for using these ciliates for cellular sensory transduction studies are that combined behavioral, electrophysiological, biochemical and genetic (both forward and reverse) approaches can all be used in these simple unicells. Behavioral bioassays are used to estimate the physiological state of the cell as well as for behavioral mutant screens and selections [33, 48, 21] and drug screening [45]. Since Paramecia are large (up to $250 \mu \mathrm{m}$ across) they can be easily used for behavioral observations, behavioral mutant screens and electrophysiological analyses. However, the smaller Tetrahymena (about 50 $\mu \mathrm{m}$ long) have the advantages of higher density cultures and the ability to generate transgenic lines and stable gene knockout mutations because of their relatively high rate of homologous recombination [15]. For example, Tetrahymena can be grown in a simple proteose peptone, axenic

Correspondence to: Dr Todd M. Hennessey, Department of Biologica Sciences, University at Buffalo, H610 Hochstetter Hall, Amherst, NY 14260, USA. Tel: +1-716-6452363; Fax: +1-716-6452975; E-mail: thennes@acsu.buffalo.edu media to a density of over 500,000 cells $/ \mathrm{ml}$ with a doubling time of less than $2 \mathrm{~h}$. For more information, see the web pages for Paramecium at: http://www.genoscope.cns.fr/ externe/English/Projets/Projet_FN/organisme_FN.html and for Tetrahymena at: http://bama.ua.edu/ hsmithso/prof/ tweb.shtml. A unique forward genetics approach, involving antisense ribosome mutagenesis, has also been developed in Tetrahymena [5]. This approach is conceptually similar to the use of transposons for tagged mutagenesis, mutant screening and selections in Drosophila because it allows for rapid identification of the sequences responsible for new mutant phenotypes. An example of reverse genetics in Tetrahymena is seen in the generation of a behavioral mutant that cannot swim backwards because of a specific dynein knockout [22]. Functional genomic information can be approached in Paramecium with the reverse genetic procedures of RNAi-by-feeding [14], homology-dependent gene silencing [46] and with electroporation, particle bombardment and microinjection transformation procedures [34]. These procedures complement the classical forward genetics approaches that have been so successful in generating important behavioral mutants in Paramecium [33, 48]. The combined advantages of these two ciliates offers a strong 'genetic dissection' approach to identifying the functional components of sensory trans- 
duction and adaptation pathways such as those involved in purinergic responses.

ATP and GTP are depolarizing chemorepellents in the ciliates Paramecium and Tetrahymena [6, 13, 30, 31, 35, 36]. These cells actively avoid micromolar concentrations of external ATP and GTP by producing avoiding reactions (AR). To view movies of these responses, see: http:// www.nsm.buffalo.edu/Bio/Research/ciliates/. Avoiding reactions are seen as repetitive bouts of backward and forward jerks which serve to re-orient the cells and bias their swimming direction away from the condition that elicited the response [28], much in the way that tumbling frequency regulates chemotaxis in bacteria [2]. For example, as a Paramecium approaches an increasing concentration gradient of a depolarizing chemorepellent, the frequency of ARs increases. Each AR reorients the cell to swim off in a new direction. If the direction takes them down the concentration gradient, the frequency of ARs decreases and they spend more time swimming straight and away from the repellent. If they venture in a path that leads them back up the gradient, AR frequency increases. This is defined as more of a chemokinetic response than a chemotaxis $[53,54]$ because it is a 'biased random walk' instead of an oriented movement. Chemokinesis to repellents can also be mediated by changes in swim speed, with cells slowing down when approaching the repellent and speeding up when swimming away from it. Chemical stimuli that cause changes in AR frequency are considered to be 'type I chemorepellents' and those that modulate swim speed are referred to as 'type II chemorepellents' [53]. High concentrations (mM) of ions, acids, bases and other compounds are considered to be type I chemorepellents. ATP and GTP differ from these classic type I repellents because they are non-toxic and are believed to involve high affinity, externally facing, membrane receptors. While ATP only elicits AR, GTP also produces a longer response in Paramecium called continuous ciliary reversal (CCR) [6]. A CCR is seen as prolonged backward swimming lasting from seconds to minutes. When Paramecia are exposed to GTP for more than $10 \mathrm{~s}$, they show repetitive bouts of CCR which are correlated with oscillating plateau depolarizations that last as long as the CCR $[6,7]$. Since ATP and GTP are not toxic to these cells, we suggest that they act as depolarizing signaling molecules, much in the way that an excitatory neurotransmitter or nociception (chemical pain) signal would.

We propose that since ATP and GTP are normally at high concentrations inside of cells, the external detection of these compounds by these ciliates may represent nearby cell lysis and whatever caused that lysis may be a condition worth avoiding. ATP has been shown to be a cytoplasmic indicator for cell lysis in animal cells and is released as a pain signal in nociception $[8,10]$. Nociception is the signaling of tissue damage or chemical irritation, typically perceived as pain or itch. In both cases (chemorepulsion and nociception) ATP is a cytoplasmic indicator of nearby cell lysis. For the ciliates, ATP and GTP can be 'blood-inthe-water' signals to represent a dangerous situation that these cells should avoid. This is supported by the observations that a fresh cytoplasmic fraction from either Paramecium or Tetrahymena elicits chemorepellent responses in both of these ciliates (personal observation). In animal cells, ATP is also released by exocytosis of nucleotide-containing granules and efflux through membrane transport proteins [9]. Therefore, it is also possible that ATP and/or GTP may be released from the ciliates as an intercellular communication strategy. However, regulated release of these compounds has yet to be documented in either of these ciliates.

\section{Behavioral responses to external ATP or GTP}

Swimming behavior is used as a convenient bioassay to estimate the sensitivities of these ciliates to external stimuli. ATP, GTP and their non-hydrolyzable analogs produce AR in Tetrahymena in a concentration-dependent manner and this can be quantitated by using the AR assay (Figure 1A). Tetrahymena have been shown to be more sensitive to GTP and $\beta-\gamma$ methylene ATP than ATP [31] (Figure 1B) and we propose that this difference is due to the presence of an ecto-ATPase which hydrolyzes ATP much better than GTP [50]. ADP and GDP are far less effective as stimuli, AMP and GMP are even less effective and adenosine and guanosine are completely ineffective in generating AR (personal observations).

The initial response of Paramecium to external ATP and GTP is also AR but the main behavioral difference is that Paramecium will also enter into repetitive bouts of prolonged backward swimming (CCR) after a few seconds in the continued presence of GTP [6]. ATP does not normally elicit repetitive CCR in Paramecium, making this a unique response to GTP. The GTP responses of Paramecium have been quantitated by a computerized motion analysis assay that measures the percent directional changes (PDC) of many cells at once [6]. This assay has been used to show that Paramecium are more responsive to GTP than ATP and they are non-responsive to the pyrimidines CTP and UTP. Paramecium do show lower concentration-dependent responses to GDP and GMP in this assay but they do not respond to guanosine [6]. It is important to note that the AR assay looks at immediate responses within the first $5 \mathrm{~s}$ after cells are first exposed to the stimulus while the PDC assay ignores the first 5-10 s because of cell movements caused by addition of cells to the observation slide. Also, the GTP-AR frequency drops often off within the first 5-10 s while the repetitive GTPCCR often take 10-15 s to develop. Therefore, the AR assay reports on immediate effects of GTP while the PDC assay has a 5-10 s delay before the repetitive CCR can be quantitated. This may be one of the reasons why ATP responses can be seen in the AR assay at concentrations where there are no detectable responses in the PDC assay. In the AR assay with Paramecium, the $\mathrm{EC}_{50}$ is about 0.01 $\mu \mathrm{M}$ for GTP [31], 10.0 $\mu \mathrm{M}$ GDP (personal observation) and $12 \mu \mathrm{M}$ for ATP [56], while the PDC assay showed $\mathrm{EC}_{50}$ values of $0.12 \mu \mathrm{M}$ for GTP [6]. $\mathrm{EC}_{50}$ values for other nucleotides were not determined by the PDC assay because 
A. Behavioral Bioassay

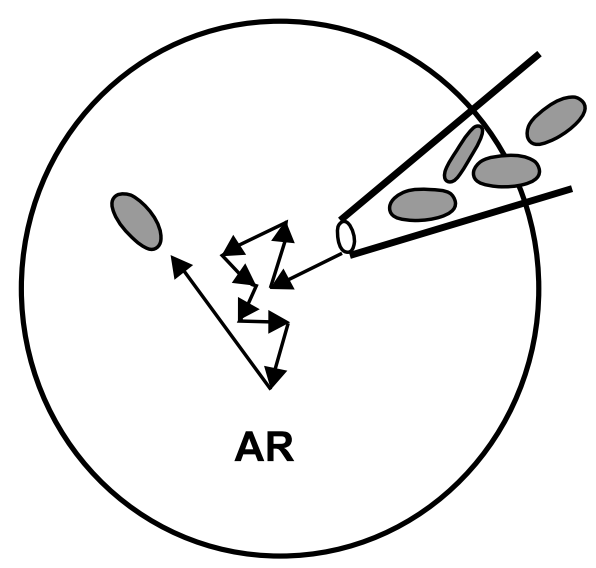

B. Concentration dependencies

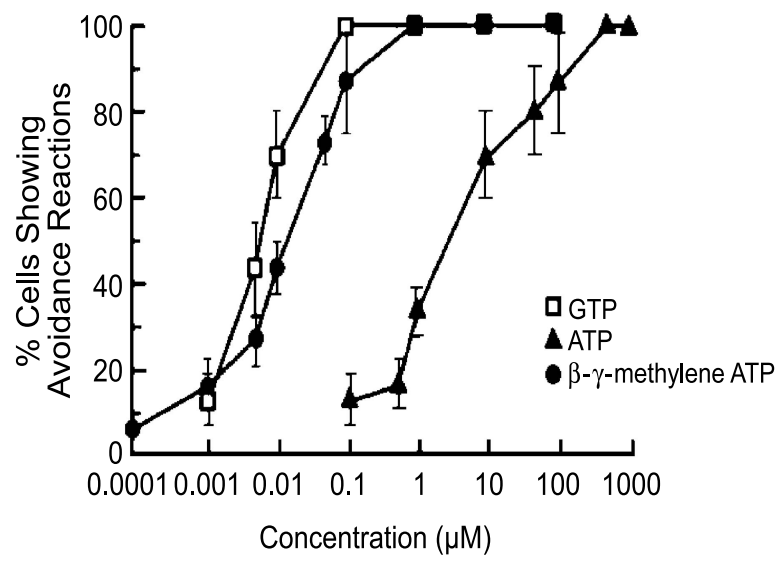

Figure 1. (A) The behavioral bioassay for avoiding reactions (AR) involves using a micropipet to transfer cells into a test solution and then observing their swimming behavior under a dissecting microscope. Individual cells are scored as either showing an AR or not. (B) The responsiveness can be quantitated by repeating this observation many times. For example, if 10 cells are observed and eight cells show AR, the percent cells showing AR = $80 \%$. For each data point in B, 3 blocks of 10 cells each were pooled so the mean \pm SD has an $n=3$. The EC 50 (concentration where the ligand is $50 \%$ effective) is about $8.0 \mathrm{nM}$ for GTP (open squares), about $10.0 \mathrm{nM}$ for $\beta-\gamma$ methylene ATP (closed circles) and $5.0 \mu \mathrm{M}$ for ATP (closed triangles) in these cells. The data shown in B were obtained with Tetrahymena and the test solution contained $10 \mathrm{mM}$ Tris-base, $0.5 \mathrm{mM}$ MOPS, $1.0 \mathrm{mM}$ disodium tartarate, $50 \mu \mathrm{M} \mathrm{CaCl}_{2}$ and $\mathrm{pH}=7.0$. (From Kim et al. [31].)

they did not saturate. The responses of Tetrahymena and Paramecium to ATP and GTP have also been quantitated by a capillary tube assay [13] and by the three-way stopcock assay for chemokinesis [53], but these assays cannot be used to measure the initial responses because they take 5-30 min for the cells to distribute within the assay apparatus.

Since the AR assay is so quick and easy, it has been used to screen for drugs that affect the responses of Tetrahymena to ATP and GTP. In Paramecium, we found that a drug that is often used as an inhibitor of P2X type ATP receptors in vertebrates, PPNDS, is actually an agonist for the ATP receptors [56]. Suramin, another common ATP receptor antagonist, is also an agonist in Paramecium (C. Wood, personal communication). The ATP responses of Tetrahymena are inhibited by GDP- $\beta-\mathrm{S}$, pertussis toxin, Calphostin $\mathrm{C}$ and Rp-cAMPs, suggesting that the ciliate ATP receptor may be a metabotropic, P2Y-like receptor [45]. However, these inhibitors have no effect on the responses of Tetrahymena to GTP. Since the effects of external GTP on internal $\mathrm{Ca}^{2+}$ levels in rat PC12 cells is also pertussis toxin-sensitive, it has been suggested that P2Y-like receptors may also be involved in this response [17]. Tyrosine kinase inhibitors have been shown to affect the GTP responses but not the ATP responses in Tetrahymena [35], supporting the idea that responses to GTP involve a sensory transduction pathway that is different than the one for ATP reception.

The PDC assay has also been used to identify drugs and mutations that affect the GTP responses of Paramecium and to show that $\mathrm{Mg}^{2+}$ and/or $\mathrm{Na}^{+}$are necessary to show the GTP-induced CCR. Several inhibitors of sarcoplasmic/ endoplasmic reticulum $\mathrm{Ca}^{2+}$-dependent ATPase (BHQ, CPA and thapsagargin) have been shown to inhibit GTPCCR in Paramecium [55], suggesting that sequestration and/or release of $\mathrm{Ca}^{2+}$ from internal stores may be involved in the repetitive CCRs seen in response to GTP. Addition of $10 \mu \mathrm{M}$ XTP (xanthosine triphosphate) was also shown to inhibit the GTP-CCR in Paramecium but XTP itself did not produce CCR [38]. The involvement of a $\mathrm{Ca}^{2+}$ dependent $\mathrm{Na}^{+}$conductance and $\mathrm{Ca}^{2+}$-dependent $\mathrm{Mg}^{2+}$ conductance in the GTP-CCR was first seen in the fact that either $0.5-1.0 \mathrm{mM} \mathrm{Mg}^{2+}$ or $4-8 \mathrm{mM} \mathrm{Na}^{+}$must be present in the external solution to see GTP-CCR in the PDC assay [7]. One behavioral mutant of Paramecium that lacks the $\mathrm{Ca}^{2+}$-dependent $\mathrm{Na}^{+}$conductance (fast-2), only shows GTP-CCR in $\mathrm{Mg}^{2+}$-containing solutions and not in $\mathrm{Na}^{+}$solutions (because it has the necessary $\mathrm{Mg}^{2+}$ conductance) while another mutant that lacks the $\mathrm{Ca}^{2+}$-dependent $\mathrm{Mg}^{2+}$ conductance (eccentric) only produces GTP-CCR in $\mathrm{Na}^{+}$-containing solutions and not in $\mathrm{Mg}^{2+}$-containing solutions [7]. This information supports the model that external GTP elicits a metabotropic activation of a pathway or pathways that leads to oscillating elevations in intracellular $\mathrm{Ca}^{2+}$ levels. These $\mathrm{Ca}^{2+}$ oscillations are mirrored in the activation of $\mathrm{Ca}^{2+}$-dependent $\mathrm{Mg}^{2+}$ and/or $\mathrm{Na}^{+}$conductances which cause sustained, oscillating depolarizations in the presence of sufficient external $\mathrm{Mg}^{2+}$ and/or $\mathrm{Na}^{+}$. It is these $\mathrm{Ca}^{2+}$-dependent oscillations that are correlated with the repetitive GTP-CCR, as described below.

\section{Electrophysiological responses to external ATP and GTP}

Electrophysiologically, each avoiding reaction (AR) is accompanied by a $\mathrm{Ca}^{2+}$-based action potential. The upstroke of the action potential is due to the activation of a ciliary, voltage-dependent $\mathrm{Ca}^{2+}$ channel and the down- 
stroke is due to a combination of $\mathrm{Ca}^{2+}$-dependent $\mathrm{Ca}^{2+}$ channel inactivation and activation of a voltage-dependent $\mathrm{K}^{+}$channel [12]. In Paramecium, intraciliary $\mathrm{Ca}^{2+}$ has been shown to be the link between somatic depolarizations (receptor potentials), action potentials and changes in swimming behavior [12, 33]. Somatic depolarizations cause ciliary voltage-dependent $\mathrm{Ca}^{2+}$-channels to open. This produces graded $\mathrm{Ca}^{2+}$-based action potentials and consequent inward $\mathrm{Ca}^{2+}$ currents. As intraciliary free $\mathrm{Ca}^{2+}$ rises, the beat frequency slows. When the free $\mathrm{Ca}^{2+}$ exceeds $10^{-6} \mathrm{M}$ the cilia reverse their direction of beat $[12,37,40]$. Therefore, if a strong enough somatic depolarization is generated, the cell swims backwards. Swimming behavior is therefore used as a convenient bioassay for estimating the electrophysiological state of these ciliates, screening for compounds which affect their electrophysiological properties and screening for behavioral mutants [21, 48]. Intracellular electrophysiological measurements in Tetrahymena have shown that their responses to depolarizing stimuli are due to electrophysiological and ionic changes that are generally similar to those of Paramecium [23]. A non-excitable behavioral mutant, called 'tnr' (Tetrahymena non-reversal), has even been described electrophysiologically in Tetrahymena [52] and it is similar to the well described 'pawn' [33] and 'cnr' (caudatum non-reversal) [51] mutants of Paramecium. This has helped to establish that Tetrahymena is also a suitable tool for studies of membrane excitation [43].

As in other types of sensory cells, depolarizing receptor potentials are necessary to generate action potentials and there is an anatomical distinction between where the receptor potentials and action potentials are generated. In Paramecium, transduction of thermal [26], mechanical [42] and chemical [54] stimuli has been shown to occur on the body (somatic) plasma membrane because the graded, sensory receptor potentials can be recorded from deciliated cells. The ciliary plasma membrane is not necessary for generating these sensory receptor potentials. In terms of the chemoresponses, classical type-I chemorepellents depolarize cells and increase the frequency of directional changes [53] but their receptors have not been identified. Heat [26] and anterior mechanical stimulation [42] also generate depolarizing receptor potentials and AR but their receptors are also unknown. Sensory receptor potentials have also been recorded in intact Tetrahymena in response to mechanical [43] and chemorepellent [23] stimulation. We propose that activation of either the external ATP or GTP receptors causes a change in somatic membrane ion conductance to depolarize the cell to a threshold level, generate action potentials and $\mathrm{AR}$ and result in chemorepulsion. GTP, ATP and $\beta$ - $\gamma$-methylene ATP-induced depolarizations are shown for Tetrahymena with small, graded action potentials riding on top of prolonged but transient depolarizing receptor potentials (Figure 2).

All of the conductances responsible for the ATP-induced receptor potentials and GTP-induced receptor potentials have not yet been described, but we have suggested that initial responses to either ATP or GTP may involve a receptor-operated $\mathrm{Ca}^{2+}$ conductance $[7,24]$ and $\mathrm{Ca}^{2+}$ -

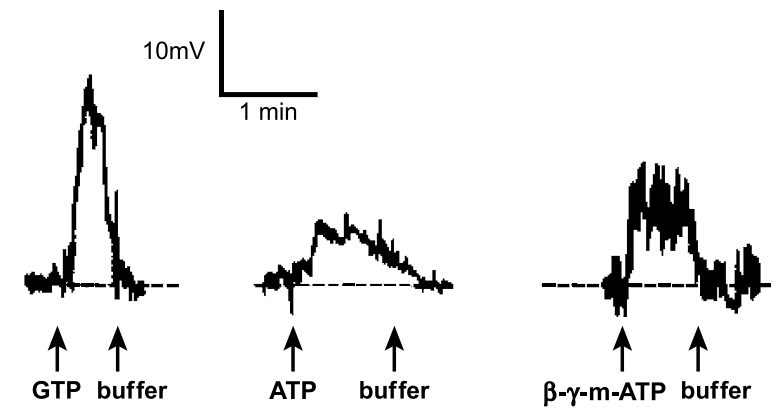

Figure 2. Sustained, reversible depolarizations were seen in Tetrahyme$n a$ in response to either $10 \mu \mathrm{M} \mathrm{GTP}, 100 \mu \mathrm{M}$ ATP or $10 \mu \mathrm{M} \beta-\gamma-$ methylene ATP. These cells were recorded under Cs-TEA conditions (2.0 $\mathrm{M} \mathrm{CsCl}$ electrodes) in a buffer containing $1.0 \mathrm{mM} \mathrm{CaCl}_{2}, 1.0 \mathrm{mM}$ MOPS, $10 \mathrm{mM}$ TEA-Cl, $\mathrm{pH}$ 7.2. In each trace, the ligand was added (at the first arrow) and removed by perfusion of the bath. (From Hennessey and Kuruvilla [23].)

activated $\mathrm{Na}^{+}$and/or $\mathrm{Mg}^{2+}$ conductances [7]. The initial $\mathrm{Ca}^{2+}$ signal may be amplified by release of $\mathrm{Ca}^{2+}$ from internal stores. However, it is also formally possible that there is a receptor-mediated release of $\mathrm{Ca}^{2+}$ from internal stores without $\mathrm{Ca}^{2+}$ influx. External GTP has been shown to cause $\mathrm{Ca}^{2+}$-induced $\mathrm{Ca}^{2+}$ release from internal stores in rat PC12 cells and elevations in internal $\mathrm{Ca}^{2+}$ levels [18, 44]. Either way, these receptor potentials (see Figures 2 and 4) are primarily due to $\mathrm{Ca}^{2+}$-dependent $\mathrm{Na}^{+}$and/or $\mathrm{Mg}^{2+}$ conductances (if sufficient $\mathrm{Na}^{+}$and/or $\mathrm{Mg}^{2+}$ is present in the stimulating solution) because GTP- and ATP-induced receptor potentials, AR and CCR, are not seen in $\mathrm{Ca}^{2+}$ only solutions in Paramecium. Also, the Paramecium mutant that lacks the $\mathrm{Ca}^{2+}$-dependent $\mathrm{Mg}^{2+}$ conductance (eccentric) does not show a measurable receptor potential in response to either ATP or GTP in $\mathrm{Mg}^{2+}$-containing solutions but does when sufficient $\mathrm{Na}^{+}$is present [7]. Similarly, the mutant that lacks the $\mathrm{Ca}^{2+}$ dependent $\mathrm{Na}^{+}$conductance (fast-2), only shows ATP- and GTP-induced receptor potentials in $\mathrm{Mg}^{2+}$-containing solutions and not in $\mathrm{Na}^{+}$solutions [7].

\section{External binding of ATP and GTP}

High affinity binding to external receptors can be assayed with these cells because they can be grown in high-density, axenic, clonal cultures where there is only one cell type present in the assay. For example, in vivo ${ }^{32} \mathrm{P}$ GTP surface binding was clearly saturable in Tetrahymena (Figure 3A) and this data can be fit by a single line on a Scatchard plot (Figure 3B), suggesting one class of high affinity GTP receptors. The estimated $K_{\mathrm{D}}$ values were about $20 \mathrm{nM}$ for both non-adapted cells de-adapted cells and the $\mathrm{B}_{\max }$ (estimated maximum number of binding sites from Scatchard plots) values suggest that the number of receptors/cell dropped from about $1.7 \times 10^{4}$ to near zero after adaptation [36]. This is consistent with a loss of surface GTP receptors during adaptation (desensitization). All of these changes were reversible following $14 \mathrm{~min}$ in a GTP-free solution. Similar 

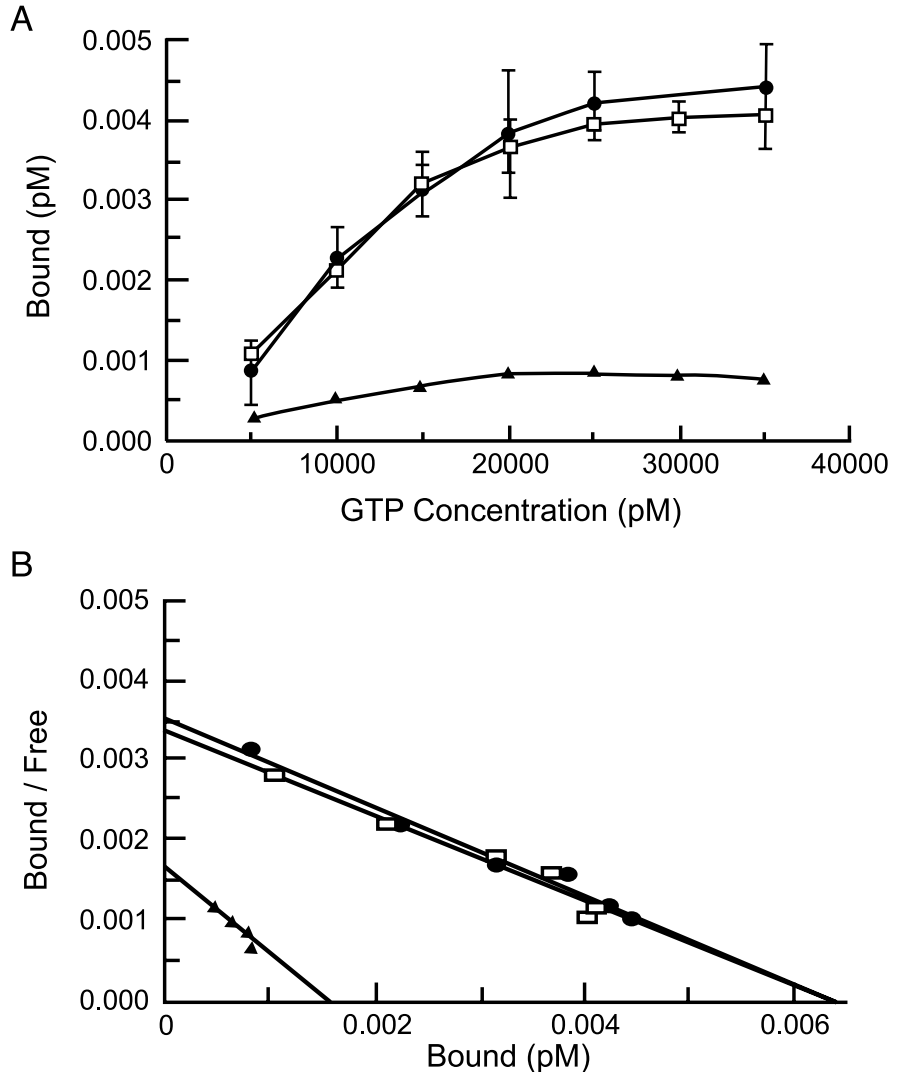

Figure 3. In vivo $\left[{ }^{32} \mathrm{P}\right]-\mathrm{GTP}$ binding to live, intact Tetrahymena showed saturable, high-affinity binding to surface receptors in both control and deadapted cells but this binding was virtually lost in adapted cells. (A) The amount of [ $\left.{ }^{32} \mathrm{P}\right]$-GTP bound to cells increased in a concentration-dependent manner in both control (open squares) and de-adapted (closed circles) cells but adapted cells (closed triangles) showed no measurable binding at any concentration tested. Each point represents the mean \pm SD of three experiments. (B) Scatchard analysis showed that the apparent $K_{\mathrm{D}}$ of control cells (open squares) and de-adapted cells (closed circles) were identical while the $B_{\max }$ values were comparable. Adapted cells showed far less binding (closed triangles). (From Kuruvilla et al. [36].)

binding and loss of surface binding sites is seen with ${ }^{32} \mathrm{P}$ ATP in Tetrahymena [31] and with ${ }^{32} \mathrm{P}$ ATP and ${ }^{32} \mathrm{P}$ GTP binding in Paramecium [30]. In all cases, the unlabeled ('cold') form of the nucleoside triphosphate was a competitive inhibitor of the binding of the radioactive form but GTP did not compete for ${ }^{32} \mathrm{P}$ ATP binding and ATP did not compete for ${ }^{32} \mathrm{P}$ GTP binding. This supports our hypothesis that there are two separate external receptors, one for ATP and the other for GTP. Similar suggestions of at least two different external binding sites for GTP and ATP have also been made in work done with external ${ }^{32} \mathrm{P}-$ GTP binding in rat PC12 cells [18] and in mouse myoblasts and myotubules [44].

\section{Chemosensory adaptation to the continued presence of ATP or GTP}

Chemosensory adaptation is seen in these ciliates as a decrease in responsiveness to a stimulus over time of exposure to that stimulus. There are two different types of adaptation to ATP and GTP in these ciliates. The first is a short-term adaptation that occurs within the first 20-40 s after a cell is transferred to a test solution containing ATP or GTP, depending upon what other ions are present in the test solution. The stimulated cell initially shows repetitive
AR but then regains forward swimming (in the continued presence of the stimulus) due to electrophysiological changes related to the termination of 'type I excitation' [47]. This involves the combined activation of voltagedependent $\mathrm{K}^{+}$conductances and inactivation of the ciliary, voltage-dependent inward $\mathrm{Ca}^{2+}$ current to bring the membrane potential and intraciliary $\mathrm{Ca}^{2+}$ concentrations back to resting levels. If the cell remains in high enough concentrations of either ATP or GTP for longer periods of time (10-15 $\mathrm{min}$ ) a long-term adaptation (see Figure 3 ) is produced due to receptor desensitization and loss of functional, externally facing receptors $[30,31,36]$. This can involve either receptor turnover or modification of the receptor to inactivate it. Behavioral adaptation may also be caused by changes in other parts of the sensory transduction pathway, such as second messengers and their contacts. Behaviorally, the distinction between short-term and long-term adaptation is that short-term adaptation can be reversed by transferring the cell to a repellent-free solution for $20 \mathrm{~s}$ while it takes $10-15 \mathrm{~min}$ in a repellentfree solution to reverse long-term adaptation. In Paramecium, it has been shown that long-term behavioral adaptation to GTP is correlated with a change in frequency of the oscillating depolarizations and decrease in external GTP binding sites [30] while ATP adaptation involves a 
decrease in the receptor potential amplitude and a decrease in external ATP binding sites [31]. No cross-adaptation was seen between these two repellent pathways because GTP adapted cells still respond to ATP and vice versa. Cells adapted to ATP or GTP had normal responses to ionic stimuli such as $40 \mathrm{mM} \mathrm{K}^{+}, 4.0 \mathrm{mM} \mathrm{Ba}^{2+}$ and $10 \mathrm{mM}$ $\mathrm{Na}^{+}$. Therefore, cells adapted to ATP or GTP were not generally less excitable but were specifically adapted to the ATP stimulus. These changes were all reversible ('deadaptation'), following $10 \mathrm{~min}$ in an ATP- or GTP-free solution. Similar behavioral and external binding changes have been seen in Tetrahymena [36].

Although we do not define it as a form of chemosensory adaptation, responsiveness to external ATP and GTP is also affected by the presence of externally facing ectoATPases which can hydrolyze these compounds and inactivate the depolarizing stimulus. In animal cells, it has been shown that soluble ecto-ATPases are involved in the deactivation of purinergic agonists in much the same way as acetylcholinesterase inactivates acetylcholine signals [29]. In this manner, membrane bound ecto-ATPases may regulate the type and amount of purinergic agonists that reach the membrane receptors. An externally facing, membrane bound ecto-ATPase has been described in Tetrahymena [50], which can serve to inactivate these purinergic signals. This ecto-ATPases has been shown to be releasable into the surrounding media and the soluble form from Tetrahymena has been purified and characterized [50]. We have proposed that this ecto-ATPase may contribute to the ATP sensitivity of Tetrahymena to the extent that it may explain why the non-hydrolyzable form of ATP ( $\beta-\gamma$ methylene ATP) is so much more effective than ATP itself (see Figure 1B). We further suggest that the reason that GTP is more effective than equimolar ATP is because the ecto-ATPase prefers ATP over GTP by 4:1, thus hydrolyzing ATP to a greater extent and lowering its effective concentration near the ATP receptor [50]. This is not due to bulk hydrolysis because this was assayed as immediate responses of single cells in a fresh $1.0 \mathrm{ml}$ volume, suggesting that the agonist must pass by many (ciliary) ecto-ATPases before it can activate the receptor. However, it is also possible that the differences in sensitivities to different ligands is due to the binding selectivity of the receptor.

\section{Two different receptors, one for ATP and one for GTP?}

We have suggested that these ciliates may have two different purinergic receptors, one for detecting ATP and the other for GTP. Purinergic receptors are classified as either P1, which prefer adenosine over nucleoside triphosphates or P2 which recognize primarily nucleoside phosphates $[1,3,4,19,41]$. However, few of the known vertebrate ATP receptors show any significant responses to micromolar concentrations of external GTP and no dedicated GTP receptor has been purified or cloned. Therefore, either the ciliate GTP receptor is a unique, new type of purinergic receptor or it may be similar to receptors that exist in some other cell type, such as those that may be involved in the responses of vertebrate cells to external GTP $[17,18,44]$. In general, the P2X class of receptors are thought to be ionotropic receptors (directly activating ion channels) whereas the $\mathrm{P} 2 \mathrm{Y}$ class of receptors are metabotropic (requiring second messengers such as cAMP and G proteins) [9]. At least eight (and possibly more) P2Y receptors have been cloned and they all share a predicted seven transmembrane spanning region with considerable homologies [9]. P2X receptors, which act as ligand-gated ion channels to mediate fast transmission in peripheral, sensory and central neurons, have also been cloned (seven different ones at this time) and they contain only two predicted transmembrane spanning regions [41]. Some of these receptors are targeted for down regulation and receptor-mediated endocytosis [11] by phosphorylation (and changes in intracellular second messengers) during desensitization [49]. Drug design for effects on purinergic responses has targeted the P2X [41] and P2Y [9] classes of receptors as well as the ecto-NTPase activities [16]. While the majority of these receptors have been identified by expression cloning in oocytes (because they are so difficult to purify), it is also very difficult to do such heterologous expression in these ciliates because of their different codon usage (for example, the glutamine codon in ciliates is a stop codon in oocytes). Pharmacological results from the lab of Heather Kuruvilla suggests that the ATP responses of Tetrahymena involve a metabotropic pathway while the GTP responses may not [45], supporting the idea that there are two separate pathways for purinergic detection in Tetrahymena. Behavioral cross-adaptation and in vivo binding experiments suggest that there may be two separate purinergic receptors, one for GTP and another for ATP (and methylene ATP) because cells that have been adapted to $10.0 \mu \mathrm{M}$ GTP for $10 \mathrm{~min}$ have lost their responsiveness to GTP but they are fully responsive to ATP and methylene ATP $[30,36]$. Similarly, ATP adapted cells still respond to GTP but they are non-responsive to methylene ATP. External binding studies showed that GTP adapted cells (which have lost their external ${ }^{32}$ P-GTP binding) still bind ${ }^{32} \mathrm{P}-\mathrm{ATP}$ and ATP adapted cells bind ${ }^{32} \mathrm{P}-\mathrm{GTP}$ even though they have lost external ${ }^{32} \mathrm{P}$-ATP binding sites. Furthermore, cold ATP is not an inhibitor of ${ }^{32}$ P-GTP binding (while cold GTP is) and vice versa. There are also differences between electrophysiological responses of ATP and GTP in Paramecium in that there are oscillating plateau depolarizations in response to GTP but not to ATP [6].

\section{Genetic dissection of the GTP response in Paramecium}

An advantage of Paramecium is the ability to screen for and select behavioral mutants, identify the genetic defect responsible for the phenotype and use this information to gain insights into the sensory transduction pathway responsible for the phenotype by 'genetic dissection' of the proposed pathway [33]. This forward genetics approach allows the cell to tell us what genes and gene products are important for an identified sensory response. In Tetrahy- 
mena, a tagged mutagenesis procedure involving antisense ribosome mutants has also been used to generate mutants, screen for a phenotype and identify the gene sequence responsible for that phenotype [5]. This procedure also holds promise as a combined forward and reverse genetics approach to identifying a sensory transduction pathway. In Paramecium, mutants were generated by nitrosoguanidine mutagenesis and screened for cells that didn't swim backwards in response to GTP [39]. A mutant was found called ginA (GTP-insensitive). This mutant was described as insensitive to GTP by the PDC assay and electrophysiological analysis confirmed that its only defect was in generating the indicative oscillating plateau depolarizations and inward currents that normally correlate with CCR. These ginA mutants respond normally to ATP and other depolarizing and hyperpolarizing stimuli. They also had normal $\mathrm{Ca}^{2+}$-dependent $\mathrm{Mg}^{2+}$ and $\mathrm{Ca}^{2+}$-dependent $\mathrm{Na}^{+}$ currents [39]. It was suggested that the defect in ginA might be in either the regulation of intracellular $\mathrm{Ca}^{2+}$ in general or, more specifically, in the proposed oscillator responsible for cyclic changes in $\mathrm{Ca}^{2+}$. However, GTPinduced changes in intracellular $\mathrm{Ca}^{2+}$ have not yet been reported. An alternative hypothesis is that the mutant is missing the GTP receptor but we found that the in vivo external ${ }^{32}$ P-GTP binding was the same in wild type and ginA with estimated $K_{\mathrm{m}}$ values of $473 \mathrm{pM}$ for ginA and $367 \mathrm{pM}$ for wild type (M. Kim, personal observations)

We have found that the ginA mutant is not insensitive to GTP but since it lacks the oscillating plateau depolarizations and repetitive CCR, it is an excellent mutant for uncovering and isolating the underlying GTP-induced receptor potential. The initial responses of ginA to external GTP are identical to those of wild type because they show the same receptor potential and consequent AR but the difference is that wild type go into repetitive CCR in GTP after $10-15 \mathrm{~s}$ while ginA do not. This CCR response is apparently not necessary for chemorepulsion because the scores of wild type and ginA are the same in the three-way stopcock chemokinesis assay [53] and the GTP-AR assay (personal observation). As shown in Figure 4, wild type show oscillating plateau depolarizations in a recording solution containing $1.0 \mathrm{mM} \mathrm{Ca}^{2+}, 0.5 \mathrm{mM} \mathrm{Mg}^{2+}$ and 2.0 $\mathrm{mM} \mathrm{Na}{ }^{+}$when $10 \mu \mathrm{M}$ GTP is perfused into the recording chamber (Figure 4A). Deciliation of wild type (Figure 4C) eliminates the ciliary $\mathrm{Ca}^{2+}$-based action potentials but does not affect the oscillating depolarizations, showing that they are generated on the body (somatic) membrane. Intact gin A mutants retain the depolarizing GTP-induced receptor potential and consequent action potentials (Figure 4B) but they lack the oscillating depolarizations. Deciliation of ginA (Figure 4D) unveils the GTP-induced somatic receptor potential by stripping away the oscillating depolarizations and action potentials. The maximal change in membrane potential seen during these transient receptor potentials was $8.8 \pm 0.95 \mathrm{mV}(n=3)$. Deciliated ginA were also used to look at other isolated receptor potentials and it was found that $10 \mu \mathrm{M}$ concentrations of ATP produced a maximal change in membrane potential of $9.5 \pm 1.7 \mathrm{mV}$, XTP produced $8.7 \pm 1.5 \mathrm{mV}$ and ITP produced $8.3 \pm 2.4$ $\mathrm{mV}$. GTP, XTP and ITP were very similar in their potencies for eliciting AR in ginA, with $100 \%$ AR seen at about $0.1 \mu \mathrm{M}$ for each. The responses of wild type to
Wild Type
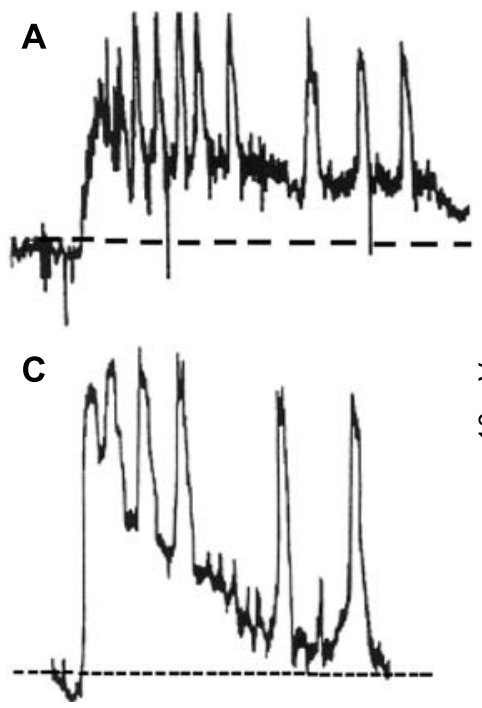

$\operatorname{gin} A$

B

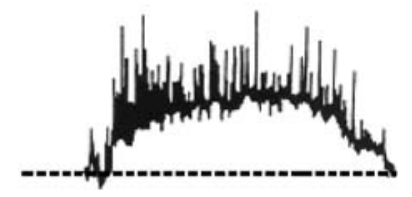

D

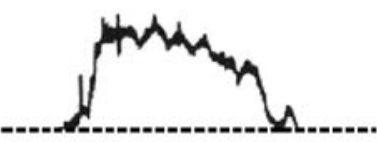

Figure 4. Electrophysiological responses of wild type and mutant Paramecium to GTP. The free running membrane potentials were recorded under constant perfusion conditions. The control solution contained $1.0 \mathrm{mM} \mathrm{CaCl}_{2}, 10 \mathrm{mM}$ Tris, $1.0 \mathrm{mM} \mathrm{MOPS}, 0.5 \mathrm{mM} \mathrm{MgCl} 2,2.0 \mathrm{mM} \mathrm{NaCl}, \mathrm{pH}=7.2$. The single recording electrode contained $500 \mathrm{mM} \mathrm{KCl}$. Perfusion with $10 \mu \mathrm{M}$ GTP began near the start of each trace and continued during the entire recording period. (A) Intact wild type show repetitive, oscillating plateau depolarizations riding on top of an underlying depolarization when $10 \mu \mathrm{M}$ GTP is perfused into the recording chamber. Some fast, graded action potentials are seen within the first few seconds. (B) The intact ginA mutant does not show any of the oscillating plateau depolarizations but does show action potentials and a transient depolarization. (C) Deciliated wild type show the same responses as intact wild type except the action potentials are lost. (D) Deciliation of ginA uncovers the isolated GTP-induced receptor potential. (From Mimekakis et al. [39] and Hennessey et al. [25].) 
XTP, ATP and ITP were the same as those of ginA because all of these compounds produced AR but not CCR. UTP and CTP produced some AR in ginA and WT but it took more than $10 \mu \mathrm{M}$ of these compounds to produce any noticeable response. At $10 \mu \mathrm{M}$ concentration, UTP produced only $0.3 \pm 0.58 \mathrm{mV}$ depolarization in deciliated ginA and CTP produced $0.7 \pm 0.58 \mathrm{mV}$ depolarization.

\section{Model for chemosensory transduction of ATP and GTP signals}

In the model below (Figure 5), the initial depolarization caused by either ATP or GTP leads to AR but forward swimming (FS) can be regained by a number of methods. Long-term adaptation can cause receptor deactivation and all of the altered parameters return to rest. A receptor antagonist would have the same effect, but no receptor antagonists have yet been found to be effective in these ciliates (personal observation). In the case of GTP stimulation in Paramecium, activation of $\mathrm{Ca}^{2+}$-dependent $\mathrm{Mg}^{2+}$ and/or $\mathrm{Na}^{+}$conductances is prolonged to convert AR into continuous ciliary reversals (CCR), presumably due to continued elevation in intraciliary $\mathrm{Ca}^{2+}$. The GTP- and ATP-induced depolarizations can be short circuited by the voltage-dependent $\mathrm{K}^{+}$or $\mathrm{Ca}^{2+}$-dependent $\mathrm{K}^{+}$conductances to bring the membrane potential back to rest and this is the most likely mechanism for short-term adaptation. $\mathrm{Ca}^{2+}$. dependent $\mathrm{Ca}^{2+}$ channel inactivation can also contribute to the repolarization by decreasing the inward $\mathrm{Ca}^{2+}$ current and this also helps to lower the intracellular $\mathrm{Ca}^{2+}$ concentrations back to resting levels. It is also possible that the voltage-dependent $\mathrm{Ca}^{2+}$ channel inactivation could contribute to a return to resting $\mathrm{Ca}^{2+}$ conductance but this process is slow and requires prolonged depolarizations [20]. The intracellular $\mathrm{Ca}^{2+}$ concentration is determined by the relative rates of events that raise this concentration $\left(\mathrm{Ca}^{2+}\right.$ influx and release of $\mathrm{Ca}^{2+}$ from internal stores) and those that lower it $\left(\mathrm{Ca}^{2+}\right.$ buffering, sequestration and efflux) so conditions that affect any of these process can affect the extent of $\mathrm{AR}$, duration of $\mathrm{CCR}$ and rate of adaptation.

\section{Responses to ATP and GTP in other ciliates}

Extracellular nucleotides have been shown to cause Euplotes to change from their normal ellipsoid shape into a 'winged' morph [32]. ATP and adenosine tetraphosphate were the most active (in concentrations of about $100 \mu \mathrm{M}$ ), followed by CTP, UTP and GTP but AMP, adenosine, cAMP, pyrophosphate and tripolyphosphate had no morphogenic activity. It was proposed that this may be due to predator-induced release of these compounds to cause a defensive morphological transformation [32]. A fluorescent analog of GTP has also been shown to bind mainly to the oral area of Tetrahymena and also stimulate cell division in starved cells [27]. Therefore, extracellular ATP and GTP could have many types of ligand-induced responses in other ciliates besides chemorepulsion.

\section{Tetrahymena genome database comparisons}

Searches of the current Tetrahymena Genome Database (http://www.tigr.org/tigr-scripts/tgi/T_index.cgi?species= t_thermophila) did not produce any sequences with high homology matches to any of the cloned P2X-type ATP receptors of vertebrates but an open reading frame has been identified, which we call TP2Y, that has similarities in the conserved regions of the $\mathrm{P} 2 \mathrm{Y}$ receptor of rat (P49651). Although the amino acid sequence homology is not very

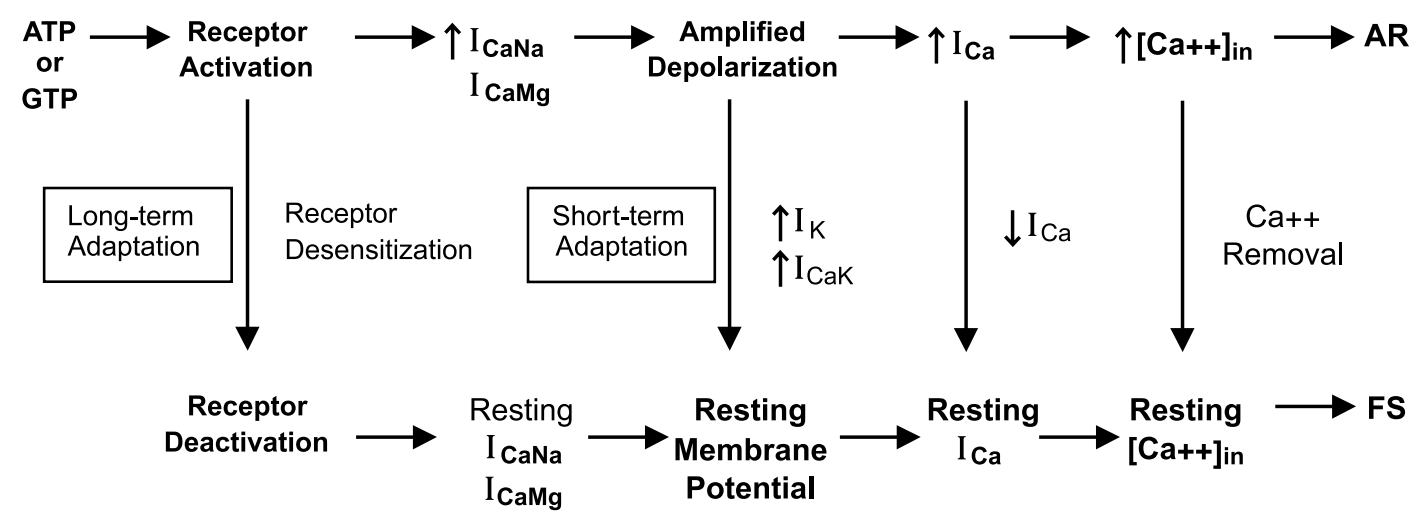

Figure 5. The proposed sensory transduction pathway. Activation of either the ATP receptor or GTP receptor results in increases in the Ca ${ }^{2+}$-dependent $\mathrm{Na}^{+}\left(\mathrm{I}_{\mathrm{CaNa}}\right)$ and/or $\mathrm{Ca}^{2+}$-dependent $\mathrm{Mg}^{2+}\left(\mathrm{I}_{\mathrm{CaMg}}\right)$ conductances to amplify the graded, depolarizing receptor potential when sufficient $\mathrm{Na}^{+}$or $\mathrm{Mg}^{2+}$ are present in the external solution. Since these are $\mathrm{Ca}^{2+}$-dependent conductances, this could happen by a receptor-activated increase in $\mathrm{Ca}^{2+}$ conductance or release of $\mathrm{Ca}^{2+}$ from internal stores. However, this mechanism has not yet been identified. Repolarization can occur by activation of the voltagedependent outward $\mathrm{K}^{+}$current $\left(\mathrm{I}_{\mathrm{K}}\right)$ or the later activating $\mathrm{Ca}^{2+}$-dependent $\mathrm{K}^{+}$current $\left(\mathrm{I}_{\mathrm{CaK}}\right)$ and by inactivation of the inward Ca ${ }^{2+}$ current $\left(\mathrm{I}_{\mathrm{Ca}}\right)$. The depolarizing receptor potential can activate the ciliary, voltage-dependent $\mathrm{Ca}^{2+}$ channel to generate an inward $\mathrm{Ca}^{2+}$ current $\left(\mathrm{I}_{\mathrm{Ca}}\right)$. The increased Ca ${ }^{2+}$ concentration in the cilia $\left(\left[\mathrm{Ca}^{2+}\right]_{\text {in }}\right)$ triggers ciliary reversal and avoiding reactions (AR). The ciliary reversals can be terminated by short-term adaptation, which brings the membrane potential and intraciliary $\mathrm{Ca}^{2+}$ concentration back to resting levels to enable forward swimming (FS). Long-term adaptation terminates the initial receptor activation, allowing all of the conductances to come back to resting levels and the cell to regain forward swimming due to the return of resting $\mathrm{Ca}^{2+}$ levels by the $\mathrm{Ca}^{2+}$ removal systems. 
high overall between the rat $\mathrm{P} 2 \mathrm{Y}$ and the Tetrahymena sequence we call TP2Y (31\% similarity), we propose that it is the protein structures that may be similar enough to generate similar functions in these two distantly related organisms. If TP2Y is a purinergic receptor, we don't know if it is the ATP receptor or the GTP receptor. Since P2Y receptors are metabotropic [9] and the ATP responses of Tetrahymena are inhibited by drugs which block P2Y responses in other cell types [45], it is possible that TP2Y codes for the ATP receptor of Tetrahymena. A putative ecto-ATPase gene has been identified in Tetrahymena that does have high homology to the conserved regions of ectoATPases from animals (personal observations), so this enzyme may play a similar role in inactivating external ATP signals. We are currently constructing mutants in TP2Y and the ecto-ATPase in Tetrahymena by macronuclear gene knockout (gene disruption) procedures [15] to see if these mutants have altered responses to external ATP and/or GTP.

\section{Acknowledgements}

This work was supported by NIH grant DK608860-01 and NSF grant MCB-9983060. I thank Christopher Wood for reading and commenting on the manuscript.

\section{References}

1. Abbracchio MP, Cattabeni F, Fredholm BB, Williams M. Purinoceptor nomenclature: A status report. Drug Dev Res 1993; 28: 207-13.

2. Adler J. How motile bacteria are attracted and repelled by chemicals: An approach to neurobiology. Biol Chem Hoppe-Seyler 1987; 368: 163-73.

3. Burnstock G. Development and perspectives of the purinoceptor concept. J Auton Pharm 1996; 16(6): 295-302.

4. Burnstock G. Purinergic signaling and vascular cell proliferation and death. Arterioscler Thromb Vasc Biol 2002; 22(3): 364-73.

5. Chilcoat ND, Elde NC, Turkewitz AP. An antisense approach to phenotype-based gene cloning in Tetrahymena. Proc Natl Acad Sci USA 2001; 98: 8709-13.

6. Clark KD, Hennessey TM, Nelson DL. External GTP alters the motility and elicits an oscillating membrane depolarization in Paramecium tetraurelia. Proc Natl Acad Sci USA 1992; 90: 3782-6.

7. Clark KD, Hennessey TM, Nelson DL, Preston RR. Extracellular GTP causes membrane-potential oscillations through the parallel activation of $\mathrm{Mg}^{2+}$ and $\mathrm{Na}^{+}$currents in Paramecium tetraurelia. J Membr Biol 1996; 157: 158-67.

8. Chizh BA, Illes P. P2X receptors and nociception. Pharmacol Rev 2001; 53(4): 553-68.

9. Communi D, Janssens R, Suarez-Huerta $\mathrm{N}$ et al. Advances in signaling by extracellular nucleotides: The role and transduction mechanisms of P2Y receptors. Cell Signal 2000; 12: 351-60.

10. Cook SP, McClesky EW. Cell damage excites nociceptors through release of cytosolic ATP. Pain 2002; 95(1-2): 41-7.

11. Ennion SJ, Evans RJ. Agonist-stimulated internalization of the ligand-gated ion channel $\mathrm{P} 2 \mathrm{X}_{1}$ in rat vas defrens. FEBS Lett 2001; 24553: 1-5.

12. Eckert R. Bioelectric control of ciliary activity. Science 1972; 176: 473-81.

13. Francis JT, Hennessey TM. Chemorepellents in Paramecium and Tetrahymena. J Eukaryot Microbiol 1995; 42: 78-83.
14. Galvani A, Sperling L. RNA interference by feeding in Paramecium. Trends Genet 2002; 18(1): 11-2.

15. Gaertig J, Gorovsky MA. Efficient mass transformation of Tetrahymena thermophilla by electroporation of conjugants. Proc Natl Acad Sci USA 1992; 89: 9196-200.

16. Gendron FP, Benrezzak O, Krugh BW et al. Purine signaling and potential new theraputic approach: Possible outcomes of NTPDase inhibition. Curr Drug Targets 2002; 3(3): 229-49.

17. Guarnieri S, Fanò G, Rathbone MP, Mariggiò MA. Cooperation in signal transduction of extracellular guanosine $5^{\prime}$ triphosphate and nerve growth factor in neuronal differentiation of PC12 cells. Neuroscience 2004; 128(4): 697-712.

18. Gysbers JW, Guarnieri S, Mariggiò MA et al. Extracellular guanosine $5^{\prime}$ triphosphate enhances nerve growth factor-induced neurite outgrowth via increases in intracellular calcium. Neuroscience 2000; 96: 817-24.

19. Harden TK, Boyer JL, Nicholas RA. $\mathrm{P}_{2}$-purinergic receptors: Subtype-associated signaling responses and structure. Annu Rev Pharmacol Toxicol 1995; 35: 541-79.

20. Hennessey TM, Kung C. Slow inactivation of the calcium current of Paramecium is dependent on voltage and not internal calcium. J Physiol 1985; 365: 165-79.

21. Hennessey TM. Ion currents of Paramecium: Effects of mutations and drugs. In Anderson PAV (ed): Evolution of the First Nervous Systems. New York: Plenum Press 1989; 215-35.

22. Hennessey TM, Kim DY, Oberski DJ et al. Inner arm dynein 1 is essential for $\mathrm{Ca}^{2+}$-dependent ciliary reversals in Tetrahymena thermophila. Cell Motil Cytoskelet 2002; 53(4): 281-88.

23. Hennessey TM, Kuruvilla HG. Electrophysiology of Tetrahymena. In Asai DJ, Forney JD (eds): Methods in Cell Biology. 1999; 62: 363-76.

24. Hennessey TM, Kim MY, Satir BH. Lysozyme acts as a chemorepellent and secretagogue in Paramecium by activating a novel receptor-operated $\mathrm{Ca}^{2+}$ conductance. J Membr Biol 1995; 148: 13-25.

25. Hennessey TM, Mimekakis JL, Nelson DL. Two separate purinergic signal transduction pathways in Paramecium. Mol Biol Cell 1998; 9: 219 a.

26. Hennessey TM, Saimi Y, Kung C. A heat-induced depolarization and its relationship to thermal avoidance. J Comp Physiol 1983; 153: 39-46.

27. Iwamoto M, Nakaoka Y. External GTP binding and induction of cell division in starved Tetrahymena thermophila. Eur J Cell Biol 2002; 81(9): 517-24

28. Jennings HS. The behavior of Infusoria. In Jennings HS (ed): Behavior of the Lower Organisms. London: Indiana University Press 1976; 47-54.

29. Kennedy C, Todorov LD, Mihaylova-Todorova S, Sneddon P. Release of soluble nucleotidases: A novel mechanism for neurotransmitter inactivation? Trends in Pharmacolog Sci 1997; 18(8): 263-6.

30. Kim MY, Kuruvilla HG, Hennessey TM. Chemosensory adaptation in Paramecium involves changes in both repellent binding and the consequent receptor potentials. J Comp Biochem Physiol 1997; 118(3): 589-97.

31. Kim MY, Kuruvilla HG, Ragu S, Hennessey TM. ATP reception and chemosensory adaptation in Tetrahymena thermophila. J Exp Biol 1999; 202(4): 407-16.

32. Kuhlmann H, Schmidt HJ. Extracellular nucleotides are active in evoking the "winged" morph of Euplotes octocarinatus. Comp Biochem Physiol 1994; 109A: 455-61.

33. Kung C. Genic mutations with altered systems of excitation in Paramecium: II Mutagenesis, screening and genetic analysis of the mutations. Genetics 1971; 69: 29-45.

34. Kung C, Saimi Y, Haynes WJ et al. Recent advances in the molecular genetics of Paramecium. J Eukaryot Microbiol 2000; 47(1): 11-4.

35. Kuruvilla HG. The GTP response of Tetrahymena thermophila involves a tyrosine kinase activity. Mol Biol Cell 2002; 13: 82a.

36. Kuruvilla HG, Kim MY, Hennessey TM. Chemosensory adaptation to lysozyme and GTP involves independently regulated receptors in 
Tetrahymena thermophila. J Eukaryot Microbiol 1997; 44(3): 263-68.

37. Machemer H. Motor control of cilia. In Gortz H-D (ed): Paramecium. Berlin: Springer-Verlag 1988; 216-33.

38. Mimekakis JL, Nelson DL. Evidence for two separate purinergic responses in Paramecium tetraurelia: XTP inhibits only oscillatory responses to GTP. J Membr Biol 1998; 163: 19-23.

39. Mimikakis JL, Nelson DL, Preston RR. Oscillating response to a purine nucleotide disrupted by mutation in Paramecium tetraurelia. Biochem J 1998; 330: 139-47.

40. Naitoh Y, Kaneko H. Reactivated triton-extracted models of Paramecium: Modification of ciliary movements by calcium ions. Science 1972; 176: 523-24.

41. North RA. Molecular physiology of P2X receptors. Physiol Rev 2002; 82(4): 1013-67.

42. Ogura A, Machemer H. Distribution of mechanoreceptor channels in the Paramecium surface membrane. J Comp Physiol 1980; 135: 233-42.

43. Onimaru H, Ohki K, Nozawa Y, Naitoh Y. Electrical properties of Tetrahymena, a suitable tool for studies on membrane excitation. Proc Jpn Acad 1980; 56: 538-43.

44. Pietrangelo T, Mariggiò MA, Lorenzon $\mathrm{P}$ et al. Characterization of specific GTP binding sites in $\mathrm{C} 2 \mathrm{C} 12$ mouse skeletal muscle cells. J Muscle Res Cell Motil 2002; 23: 107-18.

45. Rosner BN, Bartholomew JN, Gaines CD et al. Biochemical evidence for a P2Y-like receptor in Tetrahymena thermophila. J Comp Physiol, A Sens Neural Behav Physiol 2003; 189(10): $781-9$.
46. Ruiz F, Vayssie L, Klotz $\mathrm{C}$ et al. Homology-dependent gene silencing in Paramecium. Mol Biol Cell 1998; 9: 931-43.

47. Saimi Y, Hinrichsen R, Forte M, Kung C. Mutant analysis shows that the $\mathrm{Ca}^{2+}$-induced $\mathrm{K}^{+}$current shuts off one type of excitation in Paramecium. Proc Natl Acad Sci USA 1983; 80: 5112-6.

48. Saimi Y, Kung C. Behavioral genetics of Paramecium. Rev Genet 1987; 21: 47-65.

49. Schwartz AL. Receptor cell biology: Receptor-mediated endocytosis. Pediatr Res 1995; 38: 835-43.

50. Smith TM, Kirley TL, Hennessey TM. A soluble ecto-ATPase from Tetrahymena thermophila: Purification and similarity to the membrane-bound ecto-ATPase of smooth muscle. Arch Biochem Biophys 1997; 337(1): 351-59.

51. Takahashi M, Naitoh Y. Behavioral mutants of Paramecium caudatum with defective membrane electrogenesis. Nature 1978; 271: 656-58.

52. Takahashi M, Onimaru H, Naitoh Y. A mutant of Tetrahymena with a non-excitable membrane. Proc Jpn Acad 1980; 56: 585-90.

53. VanHouten JL. Two mechanisms of chemotaxis in Paramecium. J Comp Physiol 1978; 127: 167-74.

54. VanHouten J. Chemosensory transduction in Paramecium. In Armitage J, Lackie J (eds): Motility and Taxis. Cambridge: Cambridge University Press 1990; 297-322.

55. Wassenberg JJ, Clark KD, Nelson DL. Effect of SERCA pump inhibitors on chemoresponses in Paramecium. J Eukaryot Microbiol 1997; 44(6): 574-81.

56. Wood CR, Hennessey. PPNDS is an agonist, not an antagonist, for the ATP receptor of Paramecium. J Exp Biol 2002; 206: 627-36. 